\title{
Towards integrated ethical and scientific analysis of geoengineering: a research agenda
}

Nancy Tuana

Ryan L. Sriver

Toby Svoboda

Fairfield University, tsvoboda@fairfield.edu

Roman Olson

Peterwthlsvaine additional works at: https://digitalcommons.fairfield.edu/philosophy-facultypubs

Copyright 2012 Taylor and Francis. This is an Accepted Manuscript of an article published by Jaylor \& Francis in Ethics, Poljicy \& Environment 15, no. 2 (2012): 136-157], available online: http://www.tandfonline.com/10.1080/21550085.2012.685557

\section{Peer Reviewed}

\section{Repository Citation}

Tuana, Nancy; Sriver, Ryan L.; Svoboda, Toby; Olson, Roman; Irvine, Peter J.; Haqq-Misra, Jacob; and Keller, Klaus, "Towards integrated ethical and scientific analysis of geoengineering: a research agenda" (2012). Philosophy Faculty Publications. 25.

https://digitalcommons.fairfield.edu/philosophy-facultypubs/25

\section{Published Citation}

Tuana, Nancy, Ryan L. Sriver, Toby Svoboda, Roman Olson, Peter J. Irvine, Jacob Haqq-Misra, and Klaus Keller. "Towards integrated ethical and scientific analysis of geoengineering: a research agenda." Ethics, Policy \& Environment 15, no. 2 (2012): 136-157. 10.1080/21550085.2012.685557

This item has been accepted for inclusion in DigitalCommons@Fairfield by an authorized administrator of DigitalCommons@Fairfield. It is brought to you by DigitalCommons@Fairfield with permission from the rightsholder(s) and is protected by copyright and/or related rights. You are free to use this item in any way that is permitted by the copyright and related rights legislation that applies to your use. For other uses, you need to obtain permission from the rights-holder(s) directly, unless additional rights are indicated by a Creative Commons license in the record and/or on the work itself. For more information, please contact digitalcommons@fairfield.edu. 


\section{Authors}

Nancy Tuana, Ryan L. Sriver, Toby Svoboda, Roman Olson, Peter J. Irvine, Jacob Haqq-Misra, and Klaus Keller 
This is a post-print of Tuana et al., Ethics, Policy \& Environment 15:2 (2012): 136-157

http://www.tandfonline.com/doi/abs/10.1080/21550085.2012.685557

\title{
Towards Integrated Ethical and Scientific Analysis of Geoengineering:
}

A Research Agenda

\author{
Nancy Tuana ${ }^{1 *}$, Ryan Sriver ${ }^{2}$, Toby Svoboda ${ }^{3}$, Roman Tonkonojenkov ${ }^{4}$, Peter Irvine ${ }^{5}$, Jacob \\ Haqq-Misra ${ }^{6}$, and Klaus Keller ${ }^{7}$ \\ ${ }^{1}$ Department of Philosophy, Penn State, U.S.A., ntuana@psu.edu \\ ${ }^{2}$ Department of Geosciences, Penn State, U.S.A., rsriver@psu.edu \\ ${ }^{3}$ Department of Philosophy, Penn State, U.S.A, tjs328@psu.edu \\ ${ }^{4}$ Department of Geosciences, Penn State, U.S.A., rzt2-wrk@psu.edu \\ ${ }^{5}$ School of Geographical Sciences, University of Bristol, U.K., p.j.irvine@bristol.ac.uk \\ ${ }^{6}$ Department of Meteorology, Penn State, U.S.A., haqqmisra@psu.edu \\ ${ }^{7}$ Department of Geosciences, Penn State, U.S.A., klaus@psu.edu \\ *Corresponding author: 240 Sparks Building, University Park, PA 16802, Phone: (814) 865- \\ 1653
}

\begin{abstract}
Concerns about the risks of unmitigated greenhouse gas emissions are growing. At the same time, confidence that international policy agreements will succeed in considerably lowering anthropogenic greenhouse gas emissions is declining. Perhaps as a result, various geoengineering solutions are gaining attention and credibility as a way to manage climate change. Serious consideration is currently being given to proposals to cool the planet through solar-radiation management (SRM). Here we analyze how the unique and nontrivial risks of geoengineering strategies pose fundamental questions at the interface between science and ethics. To illustrate the importance of integrated ethical and scientific analysis, we define key open questions and outline a coupled scientific-ethical research agenda to analyze SRM geoengineering proposals. We identify nine key fields of coupled research including whether SRM can be tested, how quickly learning could occur, normative decisions embedded in how different climate trajectories are valued, and justice issues regarding distribution of the harms and benefits of geoengineering. To ensure that ethical analyses are coupled with scientific analyses of this form of geoengineering, we advocate that funding agencies recognize the essential nature of this coupled research by establishing an Ethical, Legal, and Social Implications (ELSI) program for SRM.
\end{abstract}

\section{Introduction}

Anthropogenic greenhouse gas emissions are projected to drive considerable climate change over the next decades to millennia (Alley et al., 2007). The projected changes in the physical and biogeochemical systems include general warming, changes in precipitation patterns, and sea-level rise. The projected impacts of these climatic changes on natural systems and 
human welfare differ across space and time. There will be winners and losers, but the average impact on livelihoods and well-being, for example, is projected to be negative (Adger et al., 2007). The key strategies in response to these climate change risks discussed in the mainstream scientific assessments are (i) adapting to the changes (i.e., reduce the impacts of a given climate change) and (ii) mitigating the greenhouse gas emissions (i.e., reducing the magnitude of the climate forcing through reductions in emissions of greenhouse gases) (Barker et al., 2007). The implementation of adaptation and mitigation strategies is, however, complicated by a number of problems. For one, anthropogenic forcing may lead to an abrupt or nonlinear threshold response in the climate system (Alley et al., 2003). In other words, the climate system may respond abruptly rather than smoothly and reversibly to the forcing, in a way where the time-scale of the response can be much shorter than the time-scale of the forcing and/or the climate system may not return to the original state once the anthropogenic forcing is removed. (Examples of these potential climate threshold responses are discussed below). Given the considerable inertia of the coupled socio-economic and climate systems, past anthropogenic climate forcings may have already committed future generations to a climate threshold response (e.g. Keller and McInerney, 2008; Keller et al., 2005; Urban and Keller, 2010). In this case a fast acting option may be desirable.

Proposals to modify the climate deliberately in order to counter global warming have gone from marginalized to mainstream in the last decade. Many studies argue that efforts to geoengineer the environment may be necessary to avoid catastrophic climate effects. Keith et al. (Keith et al., 2010, p. 426), for example, argue that geoengineering "may be the only human response that can fed off rapid and high-consequence climate impacts." Such proposals are lent credibility by the slow political momentum to reduce global levels of greenhouse gases. "The reality of climate change and the lack of international consensus on how to arrest greenhouse gas emissions makes it imperative for the survival of the planet as we know it that there be a Plan B" (Morgan et al., 2011, p. 4).

A frequently proposed geoengineering technique is solar-radiation management (SRM). SRM is designed to change the Earth's albedo in an effort to control how much solar energy reaches the planet's surface (see Crutzen, 2006). SRM proposals consider approaches such as increasing the Earth's albedo by deploying sulfate aerosol in the stratosphere or by increasing cloud cover, which scatters and reflects sunlight and thereby cools the planet for as long as the SRM is maintained. Scientists and engineers who support SRM research claim that there is an urgent need to have a strategy in place as insurance should the climate turn out to be more sensitive than expected to rising levels of greenhouse gases or to avoid high impact climate events such as loss of the Greenland ice sheet (see Keith et al., 2010); others view SRM as a bridge strategy to more effectively slow global warming while developing new energy technologies and strengthening political will to support serious mitigation strategies (see Wigley, 2006).

Analyses that propose further research and field tests of SRM argue that, if well understood, SRM eventually could be used to stabilize global temperature at a predetermined 
level and thereby avert impending threshold collapses or tipping points in the climate system. For example, some contend that SRM could be deployed quickly to stop the melting of polar ice sheets that may possibly be at a critical threshold where the melting cannot be reversed (Keith et al., 2010; MacCracken, 2009). On this view, for example, if the melting of the Greenland ice sheet were discovered to be imminent, SRM might be the only method available whose response time is short enough to prevent the threshold response (Irvine et al., 2009). This is because the injection of aerosol in the stratosphere can rapidly lower global temperatures (Robock et al., 2008), thus perhaps slowing or halting the melting of ice sheets in a more immediate manner compared to greenhouse gas mitigation strategies, which would take longer to impact temperature due to the long residency times of many atmospheric greenhouse gases, such as $\mathrm{CO}_{2}$ (Archer and Brovkin, 2008). A second example of a potential climate tipping point motivating geoengineering research is the release of methane from melting Arctic tundra (Morgan and Ricke, 2011, p. 13). Since methane is a particularly potent greenhouse gas, melting tundra serves as a positive feedback to global warming: the release of methane into the atmosphere causes increased warming, which in turn causes the release of more methane, which causes increased warming, and so on (Heimann and Reichstein, 2008). Once again, SRM potentially could be used to avert this tipping point by quickly stabilizing global temperature at a level that avoids the melting of the Arctic tundra and subsequent release of methane. Last, but not least, proponents of further SRM research also note that it could be used to avoid a shutdown of the meridional overturning circulation (MOC) (Crutzen, 2006, p. 241; MacCracken, 2006). Although there is a low probability of this particular threshold collapse occurring, a shutdown of the MOC could have drastic and potentially harmful impacts on natural and economic systems (cf. Keller et al., 2004; Vellinga and Wood, 2008). The implicit (but thus far uncertain and nontrivial to assess) assumption is that SRM can avert climate threshold responses with realistic warning times.

SRM also could be used to address other, potentially harmful impacts of climate change. For example, SRM could achieve a global temperature that slows or prevents sea-level rise from causes other than potentially highly nonlinear changes in ice sheets, e.g. due to thermosteric sealevel rise (Crutzen, 2006, p. 213; MacCracken, 2006, p. 241; Wigley, 2006). Further, proponents of SRM research suggest that SRM could reduce the risks that climate change poses to biodiversity (Crutzen, 2006, p. 214) and agricultural production (Morgan and Ricke, 2011, p. 13). Finally, should the global climate be highly sensitive to an increase in atmospheric greenhouse gases, SRM could be used to quickly address otherwise drastic increases in global temperature (Keith et al., 2010, p. 426).

Publications in support of SRM research readily admit that SRM deployment will likely have serious side-effects, which we will detail below. Reminding us that "a world cooled by managing sunlight will not be the same as one cooled by lowering emissions," Keith et al. (2010) argue nonetheless "that the risks of not doing research [on SRM] outweigh the risks of doing it," for as noted earlier they contend that it may be the only response to averting various climate catastrophes. These publications typically underscore that SRM deployment will very likely 
have serious side-effects but argue that "it would be reckless to conduct the first large-scale SRM tests in an emergency" (Keith et al., 2010, p. 456).

Studies supporting SRM research have stressed the need for international governance of SRM (see Morgan and Ricke, 2011). While important, these proposals focus primarily on geopolitical risks and give only very little attention to clarifying the ethical and justice issues that should motivate the policy needs. These studies are also mostly silent on the ethical issues surrounding SRM research itself. Given the number and potential magnitude of these ethical issues, it is essential that they become a focus of investigation as well as policy formation. We cannot in a short essay develop a comprehensive analysis of the ethical issues that should inform both research and policy regarding SRM. Our goals instead are (i) to delineate the complex coupling of scientific and ethical issues involved in SRM research, namely, computer modeling and natural event analyses) and pre-deployment for testing, as well as the ethical issues to be addressed prior to and during deployment for geoengineering, and (ii) to provide a research agenda for coupled ethical-scientific research in the area of SRM.

To appreciate the ethical issues facing SRM research, testing, and deployment, it is first important to understand the potential negative impacts of SRM, to which we turn in the next section.

\section{The Impacts of SRM}

If deployed, SRM may negatively impact both human beings and non-human organisms. First, injecting sulfate aerosol into the stratosphere could alter regional precipitation and evaporation patterns around the globe, as suggested by various computer model simulations (Irvine et al., 2010; Matthews and Caldeira, 2007; Robock et al., 2008). This occurred in the wake of the Mount Pinatubo eruption in 1991, which injected twenty megatons of $\mathrm{SO}_{2}$ into the stratosphere (Robock, 2008) and was correlated with a decrease in precipitation and occurrence of droughts in some regions (Trenberth and Dai, 2007, p. 15). Forms of SRM that inject sulfate precursor aerosol into the stratosphere could have similar effects, such as a decrease of average annual precipitation in Africa, South America, southeastern Asia (Matthews and Caldeira, 2007). Such alterations in regional precipitation could harm people in these regions by putting their food and water resources under stress and possibly leading to drought and famine (Brewer, 2007; Robock et al., 2008). Because the populations in some of these regions suffer from a high level of poverty, such impacts could have serious negative effects on basic human rights such as food security. Moreover, SRM-induced precipitation changes might affect ecosystems in ways harmful to non-human organisms, although this issue has received, thus far, scant attention in the literature (Naik et al., 2003).

Second, as indicated in various models, there are likely to be distinct regional differences in the response to different levels of solar-radiation management. Ricke et al (2010), for example argues that "the relative appeal of different levels of SRM depends on the region considered and the variable (temperature or precipitation) that is deemed most important" (p. 538). This study demonstrates that different levels of SRM would be required to sustain annual 
or seasonal water resources in one region than would be required to retain summer sea ice in another. The conclusion that the "results demonstrate that not only would 'optimal' SRM activities imply different things for different regions," but since the impacts significantly diverge the longer SRM activity is deployed, " negotiations over the amount of SRM could become inherently more difficult the longer such activities were used to compensate for rising greenhouse gas concentrations” (2010, p. 540).

Third, SRM via aerosol injections will not address the problem of ocean acidification. Since SRM does not remove $\mathrm{CO}_{2}$ from the atmosphere, the Earth's oceans would continue to become more acidic by absorbing more atmospheric $\mathrm{CO}_{2}$ (Doney et al., 2009; Fabry et al., 2008; Raven et al., 2005). High levels of $\mathrm{CO}_{2}$ alter ocean chemistry and can negatively affect the shell formation ability of marine calcifying organisms such as corals (Doney et al., 2009), with subsequent impacts on the ecosystem level (Hoegh-Guldberg et al., 2007). In addition to the harm this could cause marine organisms in such ecosystems, increased ocean acidification also could negatively affect human beings who depend on coral reefs for coastal protection and for income from fisheries and tourism (Hoegh-Guldberg et al., 2007).

Fourth, aerosol injections would reflect light from the Earth but would also convert a fraction of the direct light into diffuse light (Rasch et al., 2008). A decrease in direct light coupled with an increase in the diffuse fraction of light has been observed to result in increased photosynthesis and may result in boosted net primary productivity (Gu et al., 2003; Mercado et al., 2009). A higher fraction of diffuse light would have a negative impact on concentrating solar power production as diffuse light cannot be focused, reducing the potential for renewable energy generation from this source (Murphy, 2009).

Fifth, SRM with aerosol injections could cause ozone depletion (Rasch et al., 2008; Tilmes et al., 2008), thus allowing more ultraviolet radiation to reach the Earth's surface and increasing the risk of health impacts associated with exposure to such radiation (Moan et al., 2008).

Sixth, because aerosol SRM is relatively inexpensive (Barrett, 2008), a single state could deploy SRM unilaterally (Victor, 2008; Victor et al., 2009), potentially in a manner that serves its own perceived self-interests but has harmful side-effects people and/or ecosystems in other regions, such as, for example, decreased precipitation leading to harmful droughts.

Seventh, there is a risk that SRM could be unintentionally discontinued (e.g., due to war) after being deployed, which would allow very rapid global warming (Goes et al., 2011; Ross and Matthews, 2009). Such an abrupt increase in temperature could cause severe negative impacts on ecological and economic systems (Goes et al., 2011).

\section{SRM: Coupled Ethical-Scientific Research}

Given the potentially harmful impacts of SRM with aerosol injections, analysts have recognized that the research and potential deployment of geoengineering raises important ethical issues (Keith, 2000, pp. 277-278; Kiehl, 2006; MacCracken, 2006; Robock, 2008; Shepherd, 2009, p. 39). Morgan and Ricke, for example, (2011, p. 19) notes that "social, behavioural, legal 
and ethical issues will be important” in many cases of SRM research and Crutzen (2006, p. 217) states that, "Scientific, legal, ethical, and societal issues, regarding the climate modification scheme are many."

We concur with the view that ethical issues should be a central component of SRM research, as well as a central factor in considerations of deployment for geoengineering. However, we would stress, and will illustrate here through delineation of the ethical issues relevant to SRM research, that ethical analysis is not simply to be put into operation once the scientific and social scientific analysis is completed. On the contrary, ethically significant decisions are often embedded in the scientific analysis itself, as well as in how scientific models represent impacts and vulnerabilities. While it is already well-recognized that climate change science demands a richly interdisciplinary approach, in this essay we aim to underscore an essential, though too often overlooked, component of the interdisciplinary nature of climate science, namely that of ethical analysis.

The analysis of geoengineering proposals requires an integrated analysis that includes ethics for at least two main reasons. The first reason is that geoengineering proposals cause nontrivial risks of harm across many dimensions such as time, space, species, and socioeconomic status (Crutzen, 2006; Goes et al., 2011; Svoboda et al., 2011). A sound characterization of the underlying probabilities and risks requires a well-integrated analysis spanning fields such as Earth sciences, statistics, and economics (see Goes et al, 2011). The resulting risk characterizations are then ethically relevant inputs to both pre-deployment and deployment decisions (see Svoboda et al, 2011). As a result, the ethical and economic analyses hinge critically on a (hopefully) solid foundation provided by the natural and social sciences.

The second reason for underscoring the importance of an integrated analysis is that the ethical assessment often poses scientific questions that are not typically addressed in natural and social science assessments. Ethical considerations often suggest new areas of research that must be addressed before ethical analysis can be pursued. In other words, there can be crucial interactions (see Figures 1 and 2) from the ethical analysis to the natural and social science analysis. For example, whether a particular geoengineering proposal satisfied the requirements of inter- and/or intra-generational justice can hinge on geophysical factors involving (i) very long time scales (centuries to millennia), (ii) differences in regional impacts, and (iii) potential lowprobability / high impact events. These events are, thus far, quite poorly represented in the current generation of Earth system models (Meehl et al, 2007, Keller et al, 2008, Urban and Keller, 2009). Hence, the ethical analysis points to open and decision-relevant research questions in the natural and social sciences. 


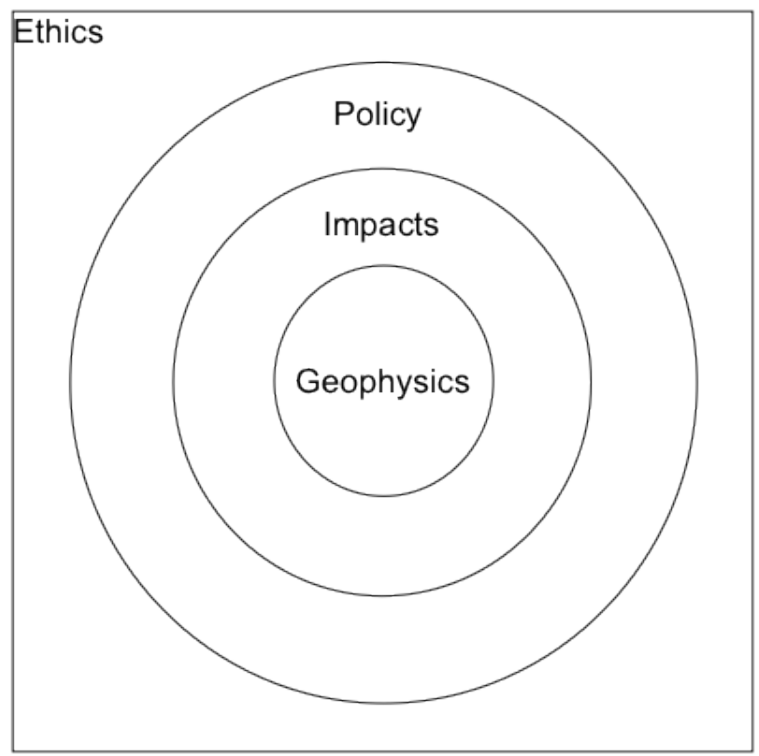

Figure 1: Conceptual map of the interdisciplinary nature of geoengineering research

We are not alone in our stance concerning the importance of ethical research for SRM. The 2009 Royal Society Report affirmed that "it is clear that ethical considerations are central to decision-making in this field" (p. 39) and concluded that "the acceptability of geoengineering will be determined as much by social, legal and political factors, as by scientific and technical factors” (p. 50). However, what has been lacking is a clear delineation of the issues and in particular: a) the ethical issues that must be addressed in the course of scientific decision-making about research and testing and $b$ ) the types of scientific knowledge and levels of confidence about models that would be ethically required to warrant responsible SRM deployment.

In demarcating the wide range and importance of these issues, we contend that the complexity of coupled ethical-scientific issues facing SRM research is analogous in terms of the complexity and importance to the types of ethical issues facing scientists working on the human genome project. Recognition of the salience and centrality of ethical issues facing human genome research led, in the 1980s, to a federally funded program to study the ethical, legal, and social implications of this research, namely, the ELSI Program of the National Center for Human Genome Research. As acknowledged by the National Human Genome Research Institute:

the planners of the Human Genome Project (HGP) recognized that the information gained from mapping and sequencing the human genome would have profound implications for individuals, families and society. While this information would have the potential to dramatically improve human health, they also realized that it would raise a number of complex ethical, legal and social issues...The Ethical, Legal and Social Implications (ELSI) Research Program was established to address these issues and has become an integral part of the HGP. ELSI provides a new approach to scientific research by identifying, analyzing and addressing the ethical, legal and social implications of human 
genetics research at the same time that the basic science is being studied. In this way, problem areas can be identified and solutions developed before scientific information is integrated into health care practice (National Human Genome Research Institute, 2010).

Our goal is to illustrate that the wide range of coupled scientific and ethical issues raised by SRM research is ground for establishing a formal program that will support this type of research. While proposals to accelerate SRM research and testing are receiving serious consideration (Morgan and Ricke 2011; Keith et al 2010), efforts to understand the ethical issues relevant to SRM research and deployment in order to identify and define the major issues of concern and develop policy options to address them have been, thus far, quite limited. We therefore advocate a model similar to that developed by the HGP and urge that SRM research include such an ELSI program to ensure that this essential research is included as part of any SRM program. While our position is compatible with the Royal Society's recognition that ethical issues are central to decision-making, this is a stronger stand in insisting that the ethical analysis be coupled with scientific analysis, and that funding agencies recognize the importance of such work through establishing funding programs for coupled ethical-scientific analyses of SRM. Furthermore, we underscore that this field of study should be strengthened prior to and included in considerations of the feasibility of SRM deployment as well as pre-deployment for testing.

The remainder of this essay is an effort to map a research agenda for coupled ethicalscientific research relevant to SRM and to delineate some of the major issues. While not claiming to have provided an exhaustive list of topics, by identifying some of the central issues, we aim to highlight the complexity of this research and underscore its importance to responsible scientific research on this topic.

\section{Delineating a Research Agenda}

Although geophysical impacts are a key element of any analysis of the viability of deploying SRM to addressing the adverse effects of global climate change, studies too often move from a discussion of likely geophysical impacts directly to proposals for governance of SRM. However, to do so ignores many other relevant issues including: a) analyses of the scientific and economic feasibility of various SRM objectives; b) careful considerations of risk and uncertainties including an analysis of the ethical dimensions of adopting various courses of action related to SRM research or deployment; and c) a full understanding of the physical and social impacts of SRM with attention paid to how the benefits and harms of those impacts are spatially and temporally distributed in order to appreciate issues of distributive and intergenerational justice. These concerns can be broadly categorized as risks due to (i) direct impacts of a given strategy and (ii) impacts arising from the interactions within the coupled natural and human systems. Finally, there are various issues surrounding the viability of implementing certain courses of action due not only to technological feasibility, but also to 
ethical, political, and legal viability. We offer Figure 2 as an effort to provide a conceptual map of this complex and interrelated field of inquiry.

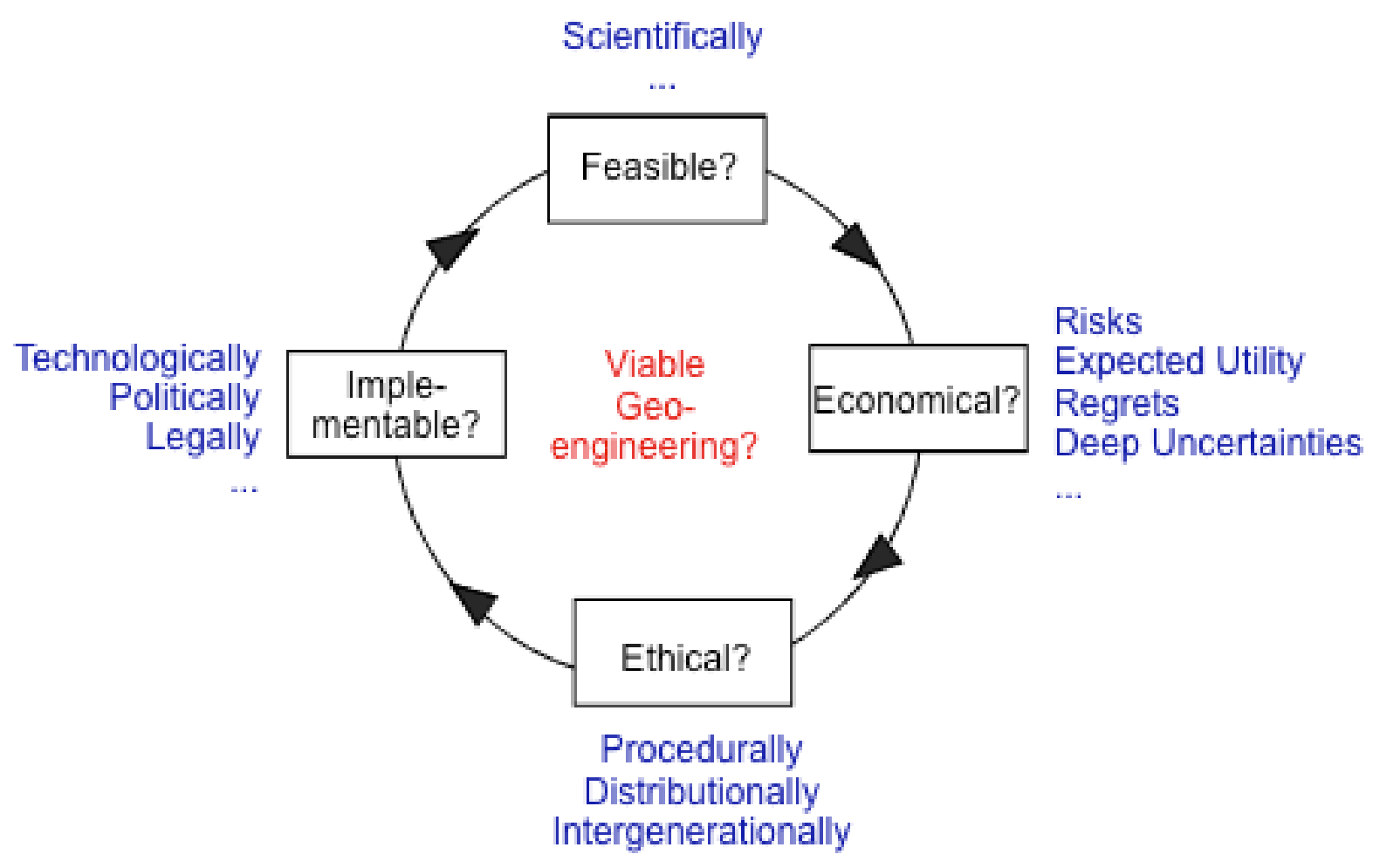

Figure 2: Conceptual map of the interdisciplinary nature of geoengineering research.

Assessing geoengineering strategies requires an analysis of the coupled scientific, economical, ethical, technological, political, and legal questions (Figure 2). As discussed below, the coupling is important, because the disciplinary questions require inputs from neighboring disciplines and because the interactions between the different system components can be crucial.

Delineation of a research agenda also requires identifying the different categories of SRM research in order to clarify the ethical issues facing each area of research, as well as addressing ethical issues that would be raised by SRM deployment. To this purpose, we delineate three categories relevant to SRM:

Category 1: Theoretical analyses such as computer modeling; analysis of natural events such as volcanic eruptions; and laboratory testing of relevant technologies.

Category 2: $\quad$ SRM pre-deployment (for testing)

Category 3: Deployment for geoengineering 
The first two categories are types of SRM research. We do not classify the third category as SRM research, though we recognize that it is likely that if SRM were deployed for geoengineering purposes, a research program would be very likely accompany it to attempt to determine if it should be continued.

Our categorization diverges from current terminology, which combines observation and analysis of natural events and pre-deployment under the rubric of "field studies" (e.g., Morgan and Ricke, 2011). While both types of research go beyond the lab, and thus could be seen as "experiments in the field," there is a significant difference between them in that analysis of natural events such as volcanic eruptions do not involve intentional manipulation of the environment. Given that intentionally acting in way that could result in changes to geophysical properties such as temperature or precipitation can itself raise ethical issues, when considering ethical analyses, it is more accurate to classify research on natural events within the same category as computer modeling and laboratory studies.

\subsection{Can Geoengineering Be Tested?}

We begin our demarcation of a research agenda with a "meta-question," namely, whether SRM can in fact be tested. At this point, it is perhaps useful to define the term "test." For the purposes of this discussion, we define "test" as a method to determine if an action results in the desired effect without unacceptable harmful side-effects. This terminology can be applied to different purposes and scales, such as small-scale developmental testing of technology, equipment and deployment, or larger-scale testing of the climate system response to SRM strategies using models or field studies.

It has been argued that there is an urgent need for research into geo-engineering options and that this research would go beyond modeling or studying natural events, by including field studies (Keith et al., 2010). Such research has been deemed a necessary step prior to partial and/or full-deployment of SRM for geoengineering and is seen as providing the basis for evaluating SRM technologies, testing the response of the system, and exploring possible unintended consequences. While there has yet to be intentional modification of the climate system to test SRM, other than some efforts at cloud whitening (cites), proposed options include small-scale deployment of stratospheric aerosol to analyze the radiative effects. Other tests have included idealized climate modeling studies examining possible effects of SRM on temperature and precipitation patterns at the regional and global scales (e.g. Matthews and Caldeira, 2007; Irvine et al., 2010; Ricke et al., 2010). In addition, volcanic eruptions can be considered natural SRM tests, because the stratospheric aerosol emitted by volcanic eruptions can alter global temperature patterns on short (annual) time scales. While these preliminary tests have provided some insight into SRM impacts and strategies, there are major challenges in extrapolating the results from idealized climate models, volcanic eruptions, and proposed small-scale field studies involving partial deployment. Inferring the system response at the global level from these limited efforts is difficult and perhaps not possible. 
Regarding climate models there are a variety of concerns. Climate models are inherently uncertain. The current generation of models does not capture fundamental physical processes important for climate due to limitations in computational resources and mechanistic understanding. Several major sources of uncertainty in climate models include vertical mixing in the ocean (Goes et al., 2011; Wunsch and Ferrari, 2004), evolution of polar ice (including ice sheets and glaciers) (Meehl et al, 2007),, radiative feedbacks in the atmosphere (Bony and Dufresne, 2005), and clouds and precipitation. These limitations lead to poor representation (or the complete lack) of important feedbacks and interactions that could significantly influence global climate conditions, such as explaining past warm paradoxes (e.g. the Pliocene and/or Eocene) and abrupt climate transitions (e.g. the Younger-Dryas event). All of these areas of uncertainty would be highly sensitive to SRM deployment, as they can influence global temperatures, precipitation patterns, and sea level rise.

To further clarify the nature of the issues, consider the issue of non-linear internal feedbacks. Interactions between uncertain climate processes may be capable of producing feedbacks between the various components of the climate system that result in bifurcations of the system. These bifurcations can lead to abrupt shifts, or transition between states, which are denoted by markedly different climate conditions. Figure 3 displays a conceptual illustration of a climate bifurcation. In the figure, the blue circle denotes a stable climate regime, such as present-day conditions, where small changes in forcing trigger a negative feedback response by the system. In other words, for small forcing (and sensitivity to forcing), the climate tends to remain in the current-day state. However, as the forcing increases, the climate system may reach a critical threshold where it transitions to unstable conditions, meaning that small changes in the forcing now result in a drastic shift in the climate state. This ultimately yields a considerably different climate state. The system may also exhibit strong memory, or hysteresis, meaning that reducing the forcing after the transition will not necessarily return the system to the original climate. The new state may also be in stable equilibrium, or in other words, there may be multiple equilibrium climate states for the same set of forcing conditions. The choice of states is dictated by the evolution of the system and the magnitude and rate of forcing. 


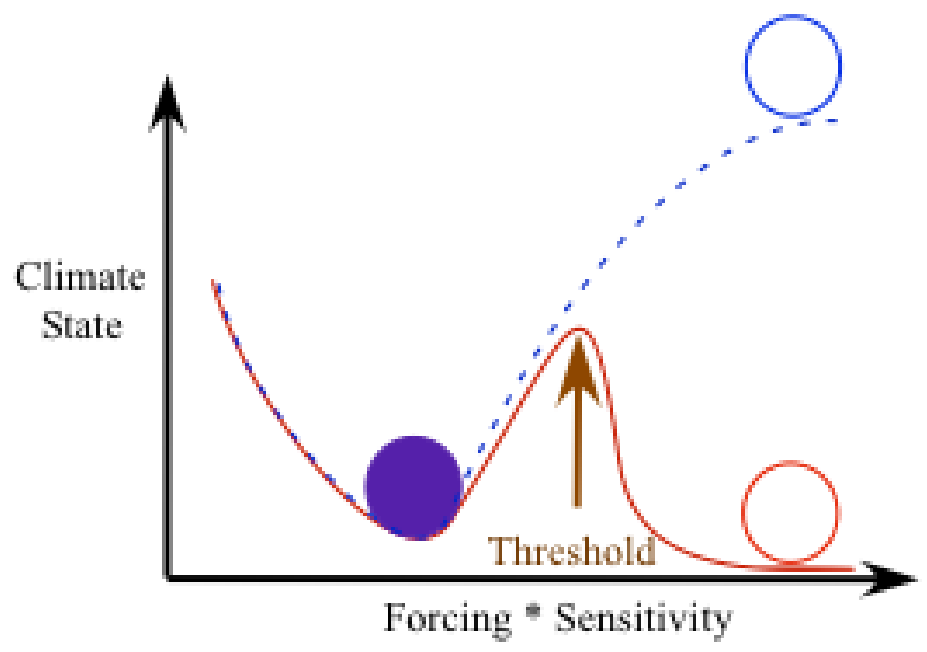

Figure 3: Simple conceptual model of a potential climate threshold response.

One example of a climate bifurcation is the shutdown of the ocean's merdional overturning circulation, which is a major contributor to global-scale transports of heat and mass by the oceans. This circulation has been shown to undergo abrupt change in the past (e.g. the during the Younger-Dryas event, (McManus et al., 2004)) leading to a global-scale climate shift, and the future of this circulation is deeply uncertain ((Meehl et al, 2007), This circulation pattern is sensitive to ocean mixing rates (Bryan, 1987; Kuhlbrodt et al., 2007), Southern Ocean winds (Toggweiler and Samuels, 1993), ocean temperature patterns, and freshening and/or salinification (Stommel, 1961). All of these processes can be directly influenced by SRM strategies, and interactions are poorly represented in climate models. Thus, the response of this circulation pattern to changes in forcing is not well understood, and feedbacks in the coupled system that are not yet captured in climate models may result in unintended impacts. These potential consequences raise additional concerns regarding SRM strategies. As a result, given that impacts related to uncertainties in key physical processes and feedbacks are not yet captured in conceptual and numerical climate models, it is difficult to rely on model results to argue for (or against) deployment of geo-engineering.

An additional SRM concern deals with the delayed system response to forcing. Large scale circulations in the atmosphere and oceans are governed by different time scales, and motions in the ocean are much slower than the atmosphere. Thus, the response times to changes in external forcing are fundamentally different, and the response by the ocean may be much later than the atmosphere for the same forcing. Because of this, oceanic perturbations by SRM strategies deployed in the atmosphere, may not manifest an oceanic response until years to decades later. The effects may reverberate through the system through teleconnection patterns stemming from long time-scale ocean-atmosphere feedbacks. An example of a relevant feedback response relates to the meridional overturning circulation, equatorial Pacific thermocline depths, and the El Nino-Southern Oscillation (Timmermann et al., 2005). In this scenario, changes in the meridional overturning strength, associated with cold water sinking at 
high northern latitudes in the Atlantic basin, can eventually lead to modifications in tropical thermocline depths in the equatorial Pacific. The thermocline marks the largest vertical temperature gradient in the ocean, and its depth in the equatorial Pacific is closely linked to the behavior of the El Nino-Southern Oscillation, which can influence temperature and precipitation patterns worldwide. This inter-basin teleconnection pattern works on timescales of decades to millennia. Thus, through long timescale feedbacks such as these, relatively short-duration forcing events by geo-engineering strategies like SRM may not be fully realized by the climate system until long after stopping SRM. The full extent of such interactions and feedbacks has yet to be explored.

It has been proposed that small-scale field studies are needed to test SRM prior to full deployment of geo-engineering strategies, such as locally injecting small quantities of aerosol into the stratosphere. Such experiments are perhaps useful for understanding the radiative processes at the particle scale and for optimizing deployment technologies, but they are likely incapable of revealing actionable early warning signals of undesirable climate responses. Findings from regional deployment will not apply to the full-scale deployment due to differences in the temporal response time between spatial scales. In other words, the local response to regional forcing is quite different from the large-scale response to global forcing, because the governing dynamical processes and time scales are fundamentally different. Past studies have pointed to volcanic activity as a possible indicator of the global response to stratospheric aerosol deployment (see Trenberth and Dai, 2007). However, these events represent a nearly instantaneous (single pulse) annual time scale forcing of the system, rather than continued deployment as would be needed with SRM. So while the spatial scale between climate forcing scenarios is now equivalent, there is still a disparity in the temporal scale of the forcing. These limitations make it difficult to employ field-testing or natural event analyses to learn about how the system will respond to SRM. Limited deployment on small spatial and temporal scales may not reveal the global scale effects, particularly for time scales beyond atmospheric residence time of aerosol, but these longer time scales may be important for understanding the ocean's response and any latent feedbacks within the coupled climate system.

This raises concerns about the viability of field tests to determine the safety of deployment. Some studies have suggested that scientists might want to go beyond computer and laboratory studies and analysis of natural events, to engage in field studies in order to gain more knowledge about SRM. One proposal, for example, maintains that while a SRM research program should begin with expanded computer simulations and laboratory studies, "because there are many important questions about these technologies that can only be answered by observing the real world, within a few years it will likely be necessary to also conduct modest low-level field testing” (Morgan and Ricke 2011, p. 17). The proposal includes a decision tree for research on SRM in which the goal or outcome from field testing is to determine whether or not SRM would have serious externalities. However, for the reasons given above, the type of learning projected from small-scale deployment may not be possible, which raises concerns about 
the justification for conducting such experiments, particularly since there is a possibility for these experiments to have negative impacts.

\subsection{What are the coupled scientific-ethical issues relevant to SRM pre-deployment for testing?}

The discussion of our meta-question about whether it is possible to test SRM leads to our first coupled scientific-ethical research field, namely what are the coupled scientific-ethical issues relevant to SRM pre-deployment for testing.

Given the limitations above described to both SRM modeling and to pre-deployment for testing impacts on the climate system, it remains unclear what the necessary temporal and spatial scales of such tests would be in order to adequately capture the response of the climate system. The general response of the climate system to SRM is deeply uncertain, due to limited understanding of key climate processes, fundamentally different atmospheric and oceanic response times, and possible non-linear feedbacks that include bifurcations in the system leading to abrupt climate shifts. It is likely that we simply may not know with confidence and the required spatial resolution how the planet will respond to geoengineering until full-deployment, and even then the extent of the impacts may not be experienced until long after SRM has ended. This is a serious complication, then, to the argument that pre-deployment for testing purposes is a necessary step to ensure the safety of deployment for geoengineering. Smaller-scale SRM deployment for testing may not provide the knowledge needed to understand the impacts of large-scale deployment, which may have serious risks of its own that we will not understand for decades after it is stopped.

This then raises a series of coupled ethical-scientific concerns regarding field-testing of SRM to determine impacts of SRM on climate systems. These include:

- What can be inferred from the limited scale experiments about the potential of a full-scale experiment, and what can not? Will this knowledge be adequate for making a responsible decision? Will this knowledge be sufficient to warrant the risks of fieldtesting?

- Is it possible to estimate the large-scale system response from a small-scale field test?

- What "side-effects" will result from pre-deployment and can they be predicted?

- What are the costs of the "side-effects" of field-testing?

- What are the bounds of permissible field testing in terms of spatial and temporal extent as well as the degree of environmental modification and intrusion?

- Are there field tests, i.e., SRM pre-deployment for testing that would incur only modest risks of significant "side-effects"? What level of confidence would be ethically adequate to conduct such tests? What can be learned from such tests?

- What scientific and ethical knowledge is required to responsibly decide whether to start SRM field-testing? What is the basis for deciding on acceptable risk levels for fieldtesting? What level of learning would justify risks of side-effects? 
- What measures of impacts would be used to determine that the costs of field-testing are higher than the benefits of field-testing and should be halted?

- What is the boundary between field-testing and deployment?

- Will some regions be more harmed by SRM field testing than others?

- Will those nations/regions/individuals harmed by SRM field-testing and/or deployment for geoengineering be compensated?

- Who will be responsible for potentially required compensation and how will compensation be determined?

\subsection{Are there political risks of conducting SRM research?}

There are various potential political risks of conducting SRM research. We here include Category One and Two activities (theoretical analyses and pre-deployment for field testing). There is some concern, for example, that geoengineering research might pose a moral hazard by causing persons to be less concerned than they otherwise would be with respect to the risks posed by climate change. For example, what is the probability that geoengineering research would impede research into other responses to climate change or reduce the political will to mitigate greenhouse gas emissions? This topic has begun to receive attention (Bunzl, 2009), but more research is needed both on the likelihood and nature of this risk, as well as other potential political risks. For example, what is the probability that conducting SRM research would lead to unregulated, unilateral, or self-interested uses? Do the political risks of pre-deployment differ from those of theoretical analyses? Some of the coupled scientific-ethical research questions relevant to political risks include:

- Could social science research collect empirical data on whether SRM research would pose a moral hazard? Can uncertainties be sufficiently reduced to support responsible action?

- Might fears concerning the possibility of SRM deployment for geoengineering trigger stronger mitigation practices?

- Might conducting SRM research lead to unregulated, unilateral, or self-interested uses?

- How inclusive should decisions on SRM research be? Would agreement between the limited number of nations 'capable' of SRM deployment be sufficient or would unanimous global consent be required?

- What is the probability that SRM research could lead to political destabilization and conflict, either, for example, a) as a result of geographically varying impacts of predeployment for testing (e.g. political unrest in countries that are or believe they are more harmed) or b) through fears that research is being done in order to use geoengineering for immoral purposes, such as unilateral deployment indifferent to harms on others or even targeting for harm particular nations or regions? 
Box 1: List of nine key questions

1) Can geoengineering be tested?

2) What are the coupled scientific-ethical issues relevant to SRM predeployment for testing?

3) Are there political risks of conducting SRM research?

4) What are feasible climate trajectories?

5) How do we value different climate trajectories?

6) What knowledge, institutions,and decision processes are needed for responsible decision-making

7) What are the distributions of benefits and harms along the trajectories for what entities? Will those harmed be compensated?

8) How fast (if at all) could we learn?

9) How is geoengineering to be controlled

\subsection{What are feasible climate trajectories?}

An important aspect of the coupled scientific-ethical dimensions of SRM for geoengineering lies in comparing the costs and benefits of geoengineering to various other kinds of climate policies. That is, what are the coupled scientific and ethical issues respectively associated with businessas-usual policies, the mitigation of greenhouse gas emissions, adaptation to climate change, geoengineering, and hybrid policies that combine emissions mitigation, adaptation, and/or geoengineering (see Wigley, 2006)? Such questions would include:

- Is SRM for partial or full deployment economically just? For example, is SRM economically feasible in comparison to a. mitigation, b. BAU, c. a combined mitigation/SRM approach? What are the costs of 'side-effects:' i.e. geophysical risks? What are the costs of an abrupt cessation of SRM? How are costs and benefits to be measured? Do our measures privilege some regions over others or have a temporal bias (e.g., unfairly discount future generations)? Should other issues, such as historical responsibility, be factored in?

- What is the most effective SRM level globally?

- What types of SRM geoengineering objectives (e.g., lowering temperatures, avoiding sea level rise) are feasible (scientifically, economically, ethically)? How are different objectives with different spatial or temporal harms and benefits to be balanced?

- Could SRM geoengineering be 'optimized' with different spatial patterns of deployment or by combining different SRM schemes? And how would optimization be defined? (Ban-Weiss and Caldeira, 2010; Robock et al., 2008)

- SRM geoengineering has been suggested as a way to prevent tipping points (cf. the discussion above). How well could tipping points be identified and how successful could SRM be at halting or even reversing these tipping point responses, and what would the impacts of the required forcings? 
- What is the probability that climate change causes severe enough damages that SRM could become a necessary response?

\subsection{How are different climate trajectories to be valued?}

Given that SRM deployment can theoretically be modified in terms of speed and intensity of deployment to target different climate trajectories, a series of coupled scientific-ethical issues about what objectives are scientifically feasible and ethically responsible constitute another field of research. In addition, since SRM will affect both temperature and precipitation, decisions will have to be made about how to compare these changes in the models that will be used to understand geophysical risks and inform policy. It is important that both the scientific as well as the ethical dimensions of methodological choices be rendered transparent. These issues include:

- What is the best way to compare and weight changes in temperature, precipitation and other climate conditions? For example, how should we trade off harmful impacts from precipitation change with respect to beneficial impacts from lower temperatures?

- How are regional variations regarding the risks of higher temperatures vs. modified precipitation to be weighted?

- If temperature and precipitation anomalies resulting from SRM cannot simply be aggregated, what is the best way to quantify them?

- Is using a regional average value for damages appropriate for either temperature or for precipitation or will doing so mask significant trends and underestimate the impact and disparity in the impact across different regions?

- How should existing climate conditions be considered when assessing the impacts of SRM-induced changes in climate? Should a dry region getting drier be treated in the same way as wet region getting drier?

\subsection{What knowledge, institutions, and decision processes are needed for responsible decision-making?}

- Should SRM research be regulated? What aspects should be regulated and why? How should such regulation be structured?

- What procedures should be put into place to determine under what conditions the predeployment for testing should be terminated as unsafe?

- Should SRM deployment for geoengineering be regulated? How should such regulation be structured?

- What procedures should be put into place to determine under what conditions the deployment should be terminated as unsafe?

- How will the target goal of geoengineering (i.e., lowering temperature and to what level, controlling sea-level rise) be determined? Who will determine this goal?

- How are speed and duration of geoengineering to be determined? 
- What procedures should be put into place to determine under what conditions the geoengineering can be stopped? What procedures should be put into place to determine whether those conditions have been met?

- How will global participation in SRM be maintained?

- What entities will be responsible for controlling SRM if deployed? For example, would it be an individual state, a group of states, or an international body?

\subsection{What are the distributions of benefits and harms along different climate trajectories, and for what entities? Will those harmed be compensated?}

Having recognized that different SRM strategies will have different risks and will likely result in different distributions of harms and benefits both spatially and temporally, another field of coupled scientific-ethical inquiry arises around who benefits and who is harmed by different climate trajectories, as well as whether harms will be compensated. For example:

- How does the optimal SRM level vary between countries and regions?

- Which climate should be the aim of SRM geoengineering, that is, which objective should be the target?

- Will regional diversity in the response to different levels of SRM make agreement about the optimal level of geoengineering difficult to achieve?

- The regions most harmed by climate change impacts are often those regions least responsible for causing it. Will SRM enlarge this gulf or make it better?

- Will SRM transfer greater risks to future generations (cf. Ross and Matthews 2009)?

- What are the consequences of abrupt cessation of SRM? How do the harms resulting from abrupt cessation correlate with the magnitude and time span of SRM?

- Regions that abstain from participating in SRM will likely still be affected. Should global participation in SRM be mandated?

- Will those nations/regions/individuals harmed by SRM be compensated? Who will be responsible for compensation? What is a just form of compensation?

- How are the harms and benefits for nonhuman organisms and ecosytems to be weighted?

\subsection{How fast (if at all) is learning possible?}

Another field of coupled ethical-scientific research involves a series of epistemic issues surrounding what can be learned from testing (or deployment) and how to act in the face of uncertainties. These include:

- How fast can uncertainties be reduced? Will deployment of SRM help or hinder learning about uncertain climate properties?

- Can threshold events be forecast with sufficient time to mitigate those events through SRM?

- How is the effectiveness of SRM to be measured?

- How are observed changes (both positive and negative) to be attributed to SRM vs. internal climate variability?

- Once deployed, can the magnitude of SRM be effectively adjusted in order to respond to observed changes in the climate system? 


\subsection{How is geoengineering to be controlled?}

The question of how geoengineering is to be controlled is a question that has a scientific element as well as a justice component. Procedural justice is an important element in responsibly deciding whose interests should be represented and the procedures for doing so. However, a just policy process must be built upon a solid scientific foundation. However, the scientific questions about feasibility and safety themselves rest upon normative decisions about what counts and what levels of confidence are adequate. Some of these coupled scientific-ethical issues include:

- What are feasible targets and safe implementation and termination speeds for SRM? How is safety defined in this context? How is this decision made?

- Are targets such as a) maintaining a stable balance of ice sheets in order to slow sea level rise or b) decreasing temperatures to return to pre-industrial temperatures or c) cooling the climate without reducing global precipitation below pre-industrial levels or d) avoid exposing significant numbers of people to "novel" climate conditions [see Irvine et al., 2010] that will require different implementation speeds and intensities scientifically, ethically, and politically feasible? How are these decisions to be made? Who will make these decisions?

- Are there some targets that require implementation speeds that would cause more harm than is ethically acceptable?

- How would SRM geoengineering deployed to achieve a certain objective be controlled in the highly variable and chaotic climate system? How would success be verified?

- How will global level of geoengineering be controlled, and how will the geoengineering be implemented and monitored?

- What groups have the scientific, political, and ethical legitimacy to make decisions about geoengineering research or deployment?

- Due to technological limitations only a limited number of countries can actually implement geoengineering. Will this be a problem?

\section{Conclusion}

Although we have attempted to identify some of the central coupled scientific-ethical issues concerning geoengineering research and deployment, our analysis is not exhaustive. It is designed instead to lay the foundation for a robust research agenda, to illustrate the essential nature of this coupled research, and to encourage funding agencies to support this coupled research by establishing an Ethical, Legal, and Social Implications (ELSI) program for SRM. 
Acknowledgements: This study was partially supported by the National Science Foundation, the Penn State Rock Ethics Institute, and the Penn State Center for Climate Risk Management. Discussions with participants in the University of Montana's workshop on The Ethics of Geoengineering: Investigating the Moral Challenges of Solar Radiation Management (http://www.umt.edu/ethics/EthicsGeoengineering/default.aspx) as well as Granger Morgan, Nathan Urban, and Rob Lempert are gratefully acknowledged (without implying agreement). All errors and opinions are, of course, ours. 


\section{References}

Adger, N., Aggarwal, P., Agrawala, S., Alcamo, J., et al. (2007) Climate Change 2007: Impacts, Adaptation and Vulnerability, Summary for Policymakers (Geneva, Switzerland: IPCC Secretariat).

Alley, R., Berntsen, T., Bindoff, N. L., Chen, Z., et al. (2007) Climate Change 2007: The Physical Science Basis, Summary for Policymakers (Geneva, Switzerland: IPCC Secretariat).

Alley, R., Marotzke, J., Nordhaus, W. D., Overpeck, J. T., et al. (2003) Abrupt Climate Change, Science 299(5615), pp. 2005-2010.

Archer, D. and Brovkin, V. (2008) The Millennial Atmospheric Lifetime of Anthropogenic $\mathrm{CO}_{2}$, Climatic Change 90(3), pp. 283-297.

Ban-Weiss, G. A., and Caldeira, K. (2010) Geoengineering as an Optimization Problem, Environmental Research Letters 5(3).

Barker, T., Bashmakov, I., Bernstein, L., Bogner, J., et al. (2007) Climate Change 2007: Mitigation, Summary for Policymakers (Geneva, Switzerland: IPCC Secretariat).

Barrett, S. (2008) The Incredible Economics of Geoengineering, Environmental and Resource Economics 39(1), pp. 45-54.

Bony, S., and Dufresne, J. L. (2005) Marine Boundary Layer Clouds at the Heart of Tropical Cloud Feedback Uncertainties in Climate Models, Geophysial Research Letters 32(20).

Brewer, P. G. (2007) Evaluating a Technological Fix for Climate, Proceedings of the National Academy of Sciences 104(24), pp. 9915-9916.

Bryan, F. (1987) Parameter Sensitivity of Primitive Equation Ocean General-Circulation Models, Journal of Physical Oceanography 17(7), pp. 970-985.

Bunzl, M. (2009) Researching Geoengineering: Should Not or Could Not?, Environmental Research Letters 4(4).

Crutzen, P. J. (2006) Albedo Enhancement by Stratospheric Sulfur Injections: A Contribution to Resolve a Policy Dilemma?, Climatic Change 77(3-4), pp. 211-219.

Doney, S. C., Fabry, V. J., Feely, R. A., and Kleypas, J. A. (2009) Ocean Acidification: The Other $\mathrm{CO}_{\mathrm{s}}$ Problem, Annual Review of Marine Science 1, pp. 169-192.

Fabry, V. J., Seibel, B. A., Feely, R. A., and Orr, J. C. (2008) Impacts of Ocean Acidification on Marine Fauna and Ecosystem Processes, ICES Journal of Marine Science: Journal du Conseil 65(3), pp. 414-432.

Goes, M., Keller, K., and Tuana, N. (2011) The Economics (or Lack Thereof) of Aerosol Geoengineering, Climatic Change, in press.

Gu, L. H., D. D. Baldocchi, S. C. Wofsy, J. W. Munger, J. J. Michalsky, S. P. Urbanski, and T. A. Boden (2003), Response of a deciduous forest to the Mount Pinatubo eruption: Enhanced photosynthesis, Science, 299(5615), 2035-2038.

Heimann, M., and Reichstein, M. (2008) Terrestrial Ecosystem Carbon Dynamics and Climate Feedbacks, Nature 451(7176), pp. 289-292.

Hoegh-Guldberg, O., Mumby, P. J., Hooten, A. J., Steneck, R. S., et al. (2007) Coral Reefs under Rapid Climate Change and Ocean Acidification, Science 318(5857), pp. 1737-1742.

National Human Genome Research Institute (2010) ELSI Planning and Evaluation History, http://www.genome.gov/10001754.

Irvine, P. J., Ridgwell, A., and Lunt, D. J. (2010) Assessing the Regional Disparities in Geoengineering Impacts, Geophysical Research Letters 37(18). 
Irvine, P. J., Lunt, D., Stone, E., and Ridgwell, A. (2009) The Fate of the Greenland Ice Sheet in a Geoengineered, High Co 2 World, Environmental Research Letters 4(4).

Keith, D. (2000) Geoengineering the Climate: History and Prospect, Annual Review of Energy and the Environment 25, pp. 245-284.

Keith, D., Parson, E., and Morgan, M. G. (2010) Research on Global Sun Block Needed Now, Nature 463(7280), pp. 426-427.

Keller, K., and McInerney, D. (2008) The Dynamics of Learning About a Climate Threshold, Climate Dynamics 30, pp. 321-332.

Keller, K., Bolker, B. M., and Bradford, D. F. (2004) Uncertain Climate Thresholds and Optimal Economic Growth, Journal of Environmental Economics and Management 48(1), pp. 723-741.

Keller, K., Hall, M., Kim, S. R., Bradford, D. F., et al. (2005) Avoiding Dangerous Anthropogenic Interference with the Climate System, Climatic Change 73(3), pp. 227238.

Kiehl, J. (2006) Geoengineering Climate Change: Treating the Symptom over the Cause?, Climatic Change 77(3), pp. 227-228.

Kuhlbrodt, T., Griesel, A., Montoya, M., Levermann, A., et al. (2007) On the Driving Processes of the Atlantic Meridional Overturning Circulation, Review of Geophysics 45(2).

MacCracken, M. C. (2006) Geoengineering: Worthy of Cautious Evaluation?, Climatic Change 77(3-4), pp. 235-243.

MacCracken, M. C. (2009) On the Possible Use of Geoengineering to Moderate Specific Climate Change Impacts, Environmental Research Letters 4(4).

Masson, D., and R. Knutti (2011), Climate model genealogy, Geophys. Res. Lett., 38(8), L08703.

Matthews, H. D., and Caldeira, K. (2007) Transient Climate--Carbon Simulations of Planetary Geoengineering, Proceedings of the National Academy of Sciences 104(24), pp. 99499954.

McManus, J. F., Francois, R., Gherardi, J. M., Keigwin, L. D., et al. (2004) Collapse and Rapid Resumption of Atlantic Meridional Circulation Linked to Deglacial Climate Changes, Nature 428(6985), pp. 834-837.

Mercado, L. M., N. Bellouin, S. Sitch, O. Boucher, C. Huntingford, M. Wild, and P. M. Cox (2009), Impact of changes in diffuse radiation on the global land carbon sink, Nature, 458(7241), 1014-1017.

Moan, J., Porojnicu, A. C., Dahlback, A., and Setlow, R. B. (2008) Addressing the Health Benefits and Risks, Involving Vitamin D or Skin Cancer, of Increased Sun Exposure, Proceedings of the National Academy of Sciences 105(2), pp. 668-673.

Morgan, M. G., and Ricke, K. (2011), Cooling the Earth through Solar Radiation Management: The Need for Research and an Approach to Its Governance (Geneva, Switzerland: International Risk Governance Council).

Murphy, D. M. (2009) Effect of Stratospheric Aerosols on Direct Sunlight and Implications for Concentrating Solar Power, Environmental Science \& Technology 43(8), pp. 2784-2786.

Naik, V., Wuebbles, D. J., DeLucia, E. H., and Foley, J. A. (2003) Influence of Geoengineered Climate on the Terrestrial Biosphere, Environmental Management 32(3), pp. 373-381.

Rasch, P. J., Tilmes, S., Turco, R. P., Robock, A., et al. (2008) An Overview of Geoengineering of Climate Using Stratospheric Sulphate Aerosols, Philosophical Transactions of the Royal Society A - Mathematical Physical and Engineering Sciences 366(1882), pp. 40074037. 
Raven, J., Caldeira, K., Elderfield, H., Hoegh-Guldberg, O., et al. (2005), Ocean Acidification Due to Increasing Atmospheric Carbon Dioxide (London: Royal Society).

Robock, A. (2008) 20 Reasons Why Geoengineering May Be a Bad Idea, Bulletin of the Atomic Scientists 64(2), pp. 14-18.

Robock, A., Oman, L., and Stenchikov, G. L. (2008) Regional Climate Responses to Geoengineering with Tropical $\mathrm{SO}_{2}$ Injections, Journal of Geophysical Research-Atmospheres 113.

Ross, A., and Matthews, H. D. (2009) Climate Engineering and the Risk of Rapid Climate Change, Environmental Research Letters 4(4).

Schneider, S. H., Semenov, S., Patwardhan, A., Burton, I., et al. (2007) Assessing Key Vulnerabilities and the Risk from Climate Change, in: Parry, M. L., Canziani, O. F., Palutikof, P. J., Linden, V. D., et al. (Eds.) Climate Change 2007: Impacts, Adaptation and Vulnerability, Contribution of Working Group II to the Fourth Assessment Report of the Intergovernmental Panel on Climate Change, pp. 779-810, (Cambridge: Cambridge University Press).

Shepherd, J., Caldeira, K., Cox, P., Haigh, J., et al. (2009) Geoengineering the Climate: Science, Governance and Uncertainty (London: The Royal Society).

Stommel, H. (1961) Thermohaline Convection with Two Stable Regimes of Flow, Tellus 13(2), pp. 224-230.

Svoboda, T., Keller, K., Goes, M., and Tuana, N. (2011) Sulfate Aerosol Geoengineering: The Question of Justice, Public Affairs Quarterly, in press.

Tilmes, S., Müller, R., and Salawitch, R. (2008) The Sensitivity of Polar Ozone Depletion to Proposed Geoengineering Schemes, Science 320(5880), pp. 1201-1204.

Timmermann, A., S.-I. An, U. Krebs, and H. Goosse (2005), ENSO suppression due to weakening of the North Atlantic thermohaline circulation, J. Clim., 18, 3122-3139.

Toggweiler, J. R. and Samuels, B. L. (1993) Is the Magnitude of the Deep Outflow from the Atlantic Ocean Actually Governed by Southern Hemisphere Winds?, in: Heimann, M. (Ed.) The Global Carbon Cycle, pp. 301-331, (Heidelberg: Springer-Verlag).

Trenberth, K. E., and Dai, A. (2007) Effects of Mount Pinatubo Volcanic Eruption on the Hydrological Cycle as an Analog of Geoengineering, Geophysical Research Letters 34(15).

Urban, N. M., and Keller, K. (2010) Probabilistic Hindcasts and Projections of the Coupled Climate, Carbon Cycle and Atlantic Meridional Overturning Circulation System: A Bayesian Fusion of Century-Scale Observations with a Simple Model, Tellus Series ADynamic Meteorology and Oceanography 62(5), pp. 737-750.

Vellinga, M., and Wood, R. A. (2008) Impacts of Thermohaline Circulation Shutdown in the Twenty-First Century, Climatic Change 91(1-2), pp. 43-63.

Victor, D. G. (2008) On the Regulation of Geoengineering, Oxford Review of Economic Policy 24(2), pp. 322-336.

Victor, D. G., Morgan, M. G., Apt, J., Steinbruner, J., et al. (2009) The Geoengineering Option, Foreign Affairs 88(2), pp. 64-76.

Wigley, T. M. L. (2006) A Combined Mitigation/Geoengineering Approach to Climate Stabilization, Science 314(5798), pp. 452-454.

Wunsch, C., and Ferrari, R. (2004) Vertical Mixing, Energy, and the General Circulation of the Oceans, Annual Review of Fluid Mechanics 36(1), pp. 281-314. 